\title{
Initial Studies of Fish Otoliths Aid in Understanding the Jones Branch Site (Late Oligocene) in Southeastern Mississippi
}

\author{
Dr. Gary L. Stringer \\ Museum of Natural History \\ University of Louisiana - Monroe
}
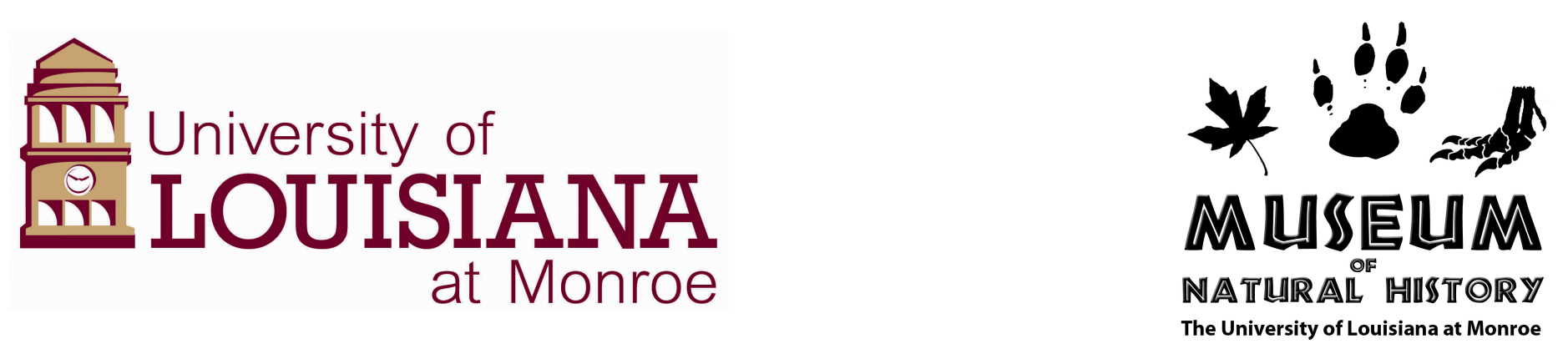


\section{IMPORTANCE OF OTOLITHS AT THE JONES BRANCH SITE}

Teleostean ear stones or otoliths, part of the fish's acousticolateralis system, supply important taxonomic information that can augment skeletal remains. At many sites, especially in Gulf Coast and Caribbean deposits, otoliths actually provide greater insight into the bony fishes than skeletal fossils.

Otoliths can furnish salient and significant paleogeography and paleoecology data.

Finally, otoliths can provide general biostratigraphic parameters.

Jones Branch otolith assemblage can contribute in all these areas.
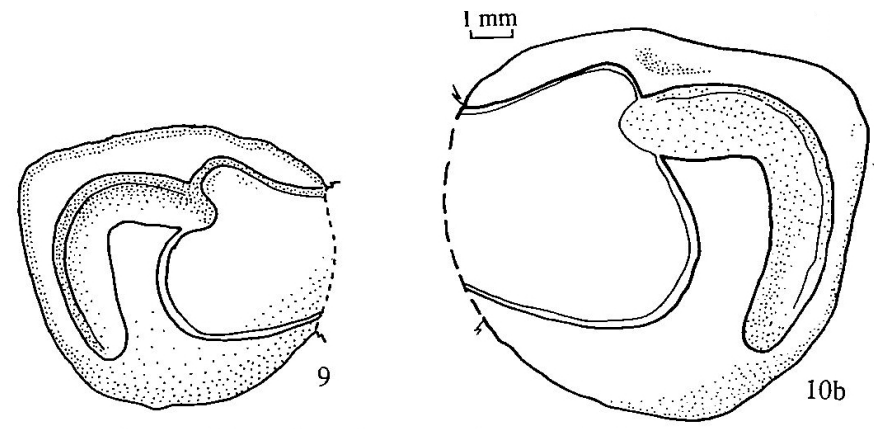

Aplodinotus gemma Koken, 1888 


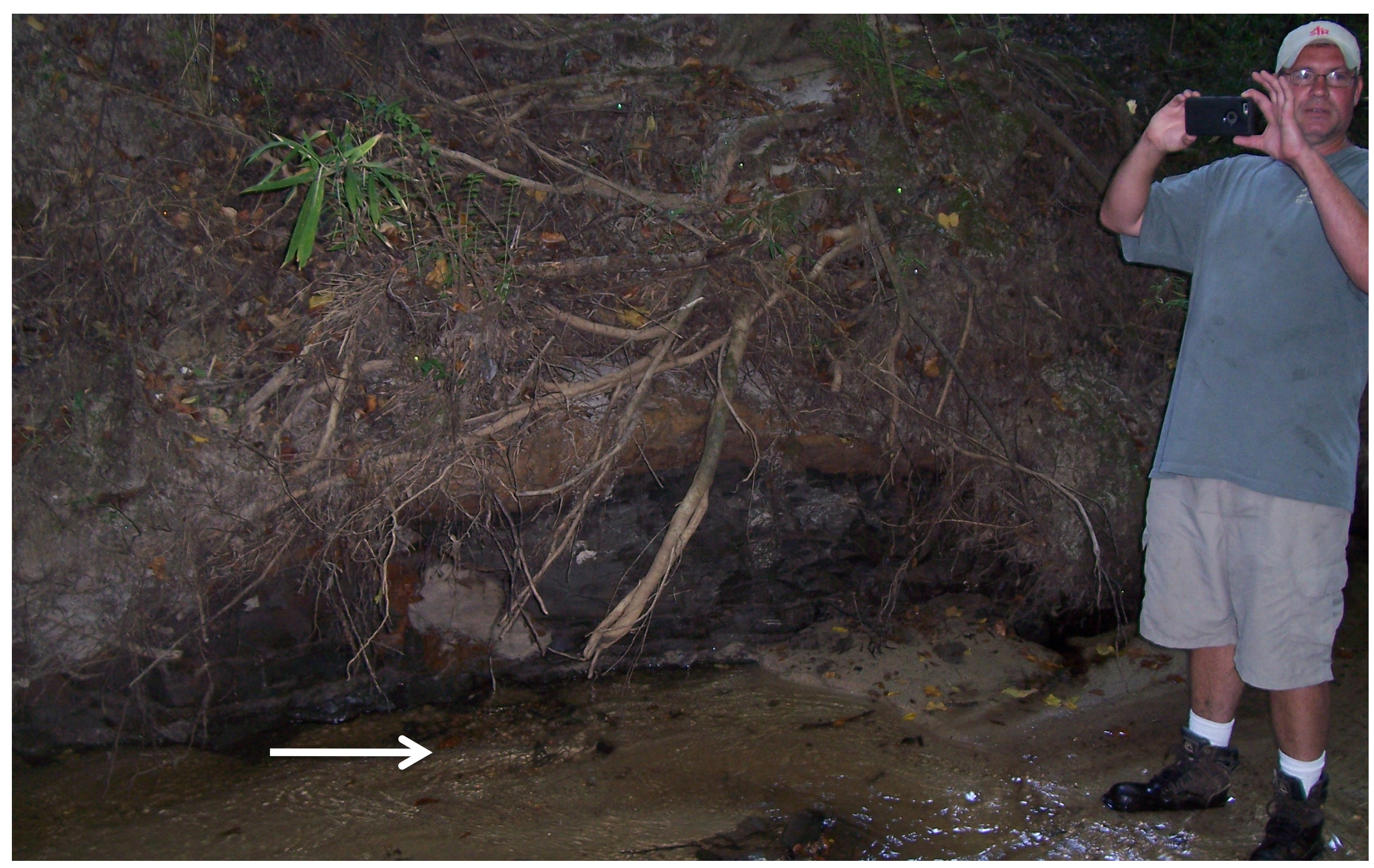

Best shell hash layer was below water level (white arrow). However, about $75 \mathrm{~kg}$ (164.6 lbs) of shell hash from Catahoula Formation was collected. James Starnes (MS Office of Geology) for scale. 


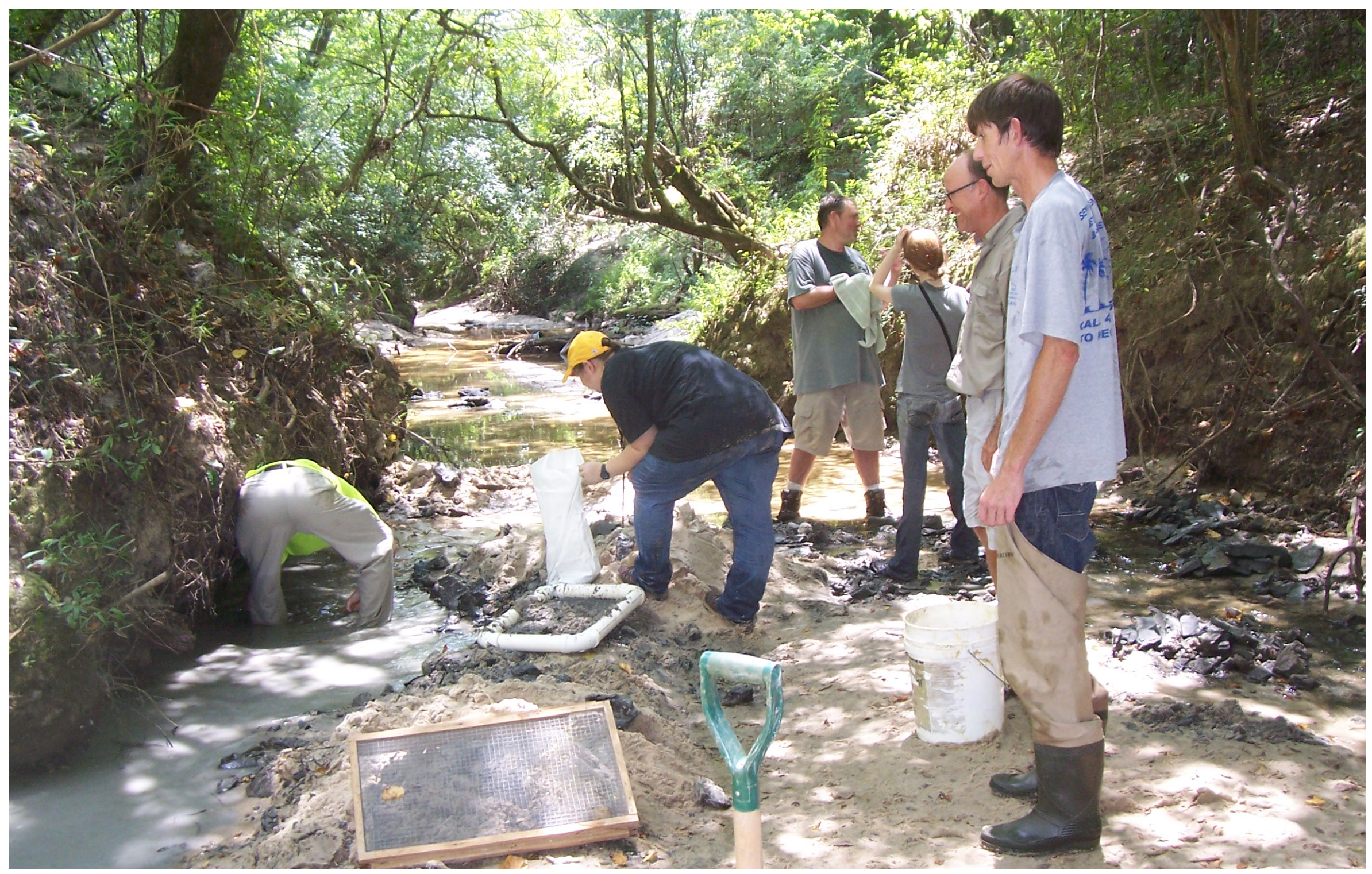

Difficulty of collecting demonstrated by MS Museum of Natural Science (MMNS) George Phillips' awkward and uncomfortable posture in the creek. 


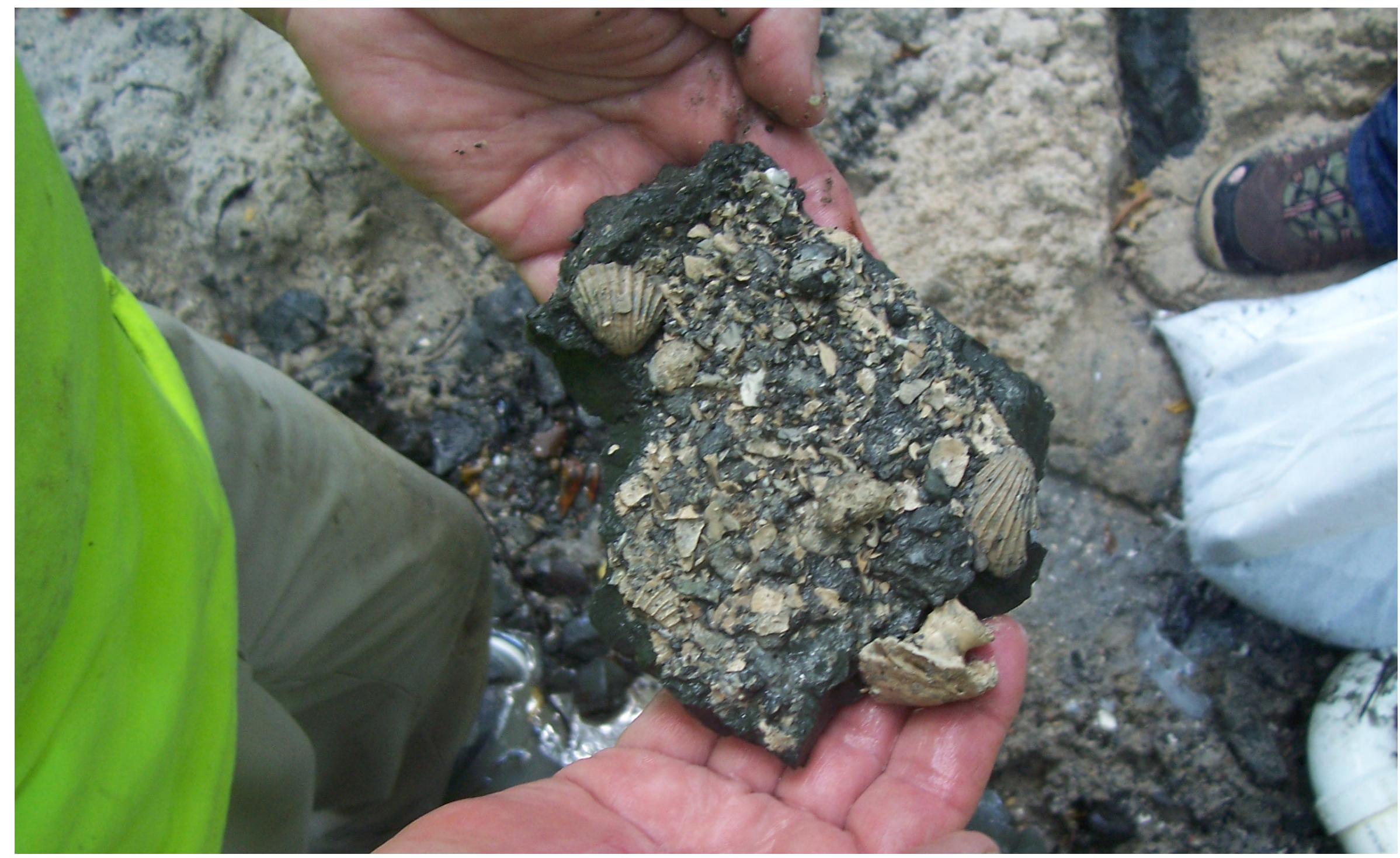

Sample from the lower portion of the Catahoula Formation showing the thin marine layer (shell hash). 


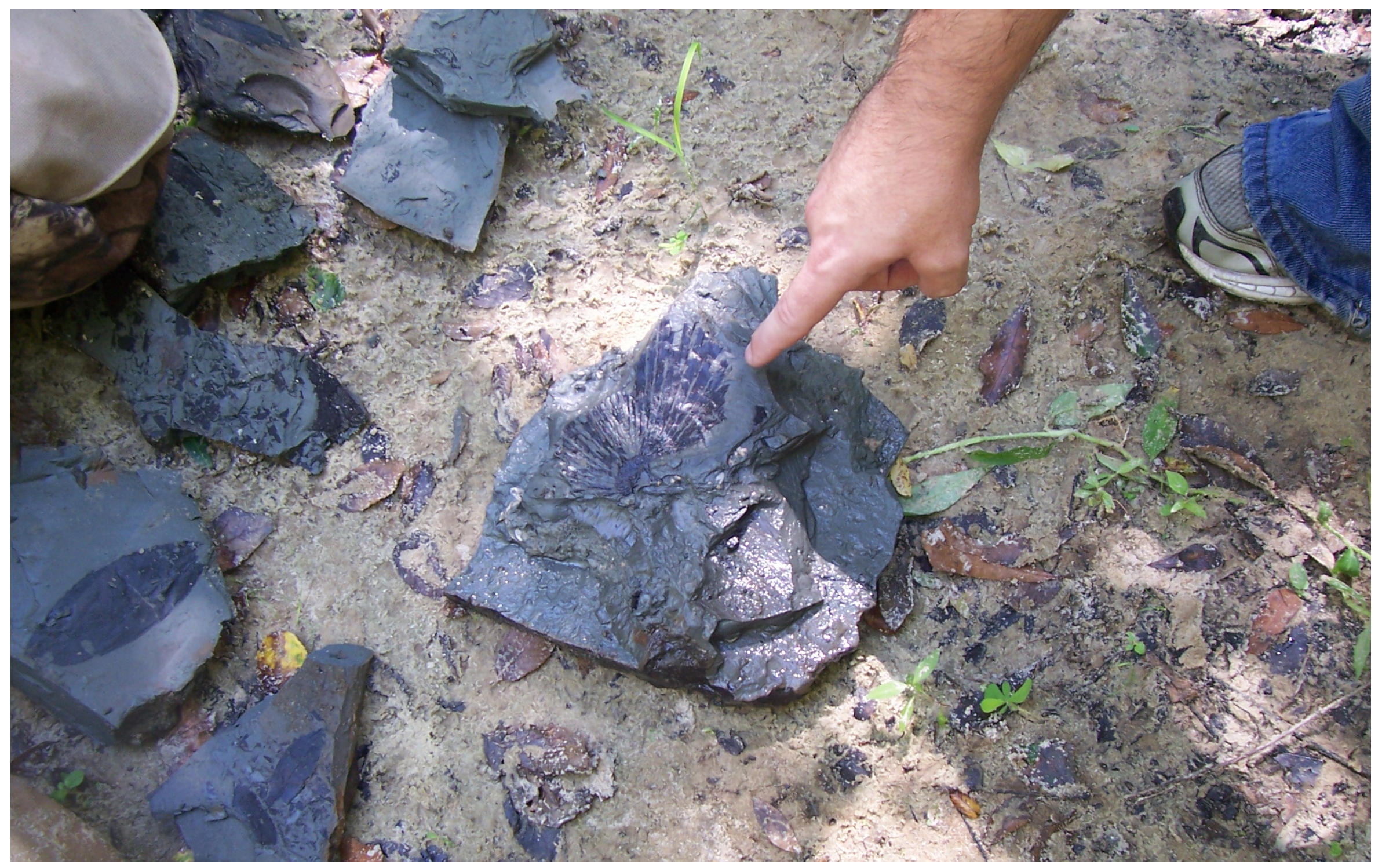

Rare occurrence for me: collecting otoliths in close association with excellently preserved, carbonized floral remains. 


\section{METHODOLOGY}

As noted earlier, $75 \mathrm{~kg}$ of basal Catahoula Formation was collected. Emphasis was placed on procuring the shell hash layer. All otoliths for this study were obtained by bulk sampling (no otoliths recovered on the surface).

Bulk samples were air dried completely before water screening (no additives).

Bulk sample produced an amazing $14 \mathrm{~kg}$ (31 pounds) of residue (30 mesh and above). Smaller mesh was retained but not examined. Very large mesh was sorted by naked eye. All residue 5 mesh and smaller was microscopically examined.

Otolith specimens were also obtained on loan from the MMNS. 


\section{METHODOLOGY (continued)}

Approximately $9.6 \mathrm{~kg}$ ( $21.2 \mathrm{lbs})$ of residue examined with an Olympus binocular stereo-zoom microscope (0.67 to $4.0 \mathrm{x}$ ).

Standard micropaleontology tray $(5 \times 9 \mathrm{~cm})$ utilized. Based on weight of one tray of residue, estimated that 2,345 trays were examined to obtain otolith specimens.

Examining residue was quite difficult: amount of residue, rarity of otoliths, presence of hardened clay clasts (even after repeated water screening), very abundant quartz sand grains, and effects of reworking, erosion, etc. Many of clay clasts and mollusk shells were rounded and resembled the shape of otoliths. 


\section{PRELIMINARY RESULTS}

Most of the otoliths were poorly preserved, and many had to be treated with Butvar (most of the MMNS specimens were treated). Poor preservation (aragonitic dissolution) could be related to exposure to fluids at sediment-water interface, in situ fluids after burial in near surface sediments, or meteoric diagenesis.

In spite of the limitations of the study of the otoliths (scarcity of otoliths, extremely friable and eroded condition of many specimens, and small size), 295 identifiable otoliths were recovered along with many non-descript fragments.

Some otoliths could only be assigned to family levels due to preservation. Still, otoliths provided evidence of bony fishes representing at least five families and nine taxa. 
Bony fishes represented by otoliths from the Catahoula Formation at the Jones Branch Site were as follows:

\section{One albulid (bonefishes),}

Two taxa of congrids (conger eels),

One sparid (porgies),

At least four taxa of sciaenids (drums).

It should be noted that other taxa are possible in the groups identified as Perciformes indeterminate and Sciaenidae indeterminate. However even with the possibility of several additional species, the Jones Branch otolith assemblage is quite restricted in diversity. 
Otolith assemblage from the Catahoula Formation at the Jones Branch Site was dominated by sciaenids or drums. The family Sciaenidae accounted for $84.75 \%$ of the total otoliths. Four sciaenid taxa also represented $55.56 \%$ of the total taxa as indicated by otoliths. Three of the sciaenid taxa are known only from the Oligocene (Aplodinotus gemma, Aplodinotus distortus, and "Sciaenida" radians).

Albulids or bonefishes were the second most abundant group but comprised only $2.71 \%$ of the total otoliths. The dominance of sciaenid taxa is quite evident and pronounced.

Several of the Jones Branch taxa were represented by only one or two otoliths (congrids, sparids, flounders). 
By far, the most abundant species in the otolith assemblage of the Catahoula Formation at the Jones Branch Locality were the following sciaenid taxa:

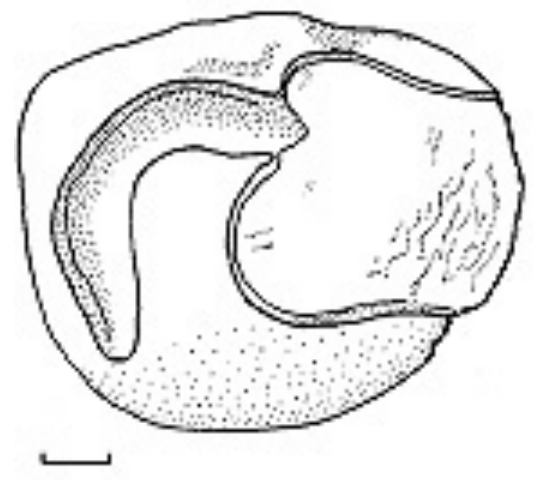

Sciaena pseudoradians

(Dante \& Frizzell, 1965)

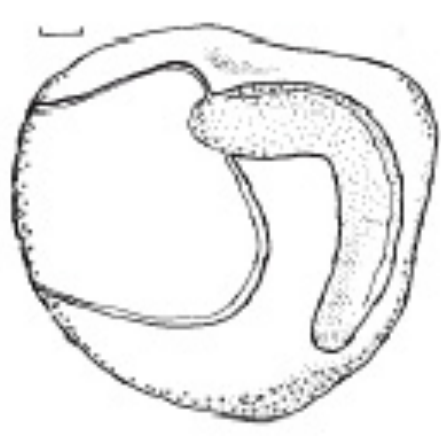

Aplodinotus gemma

Koken, 1888

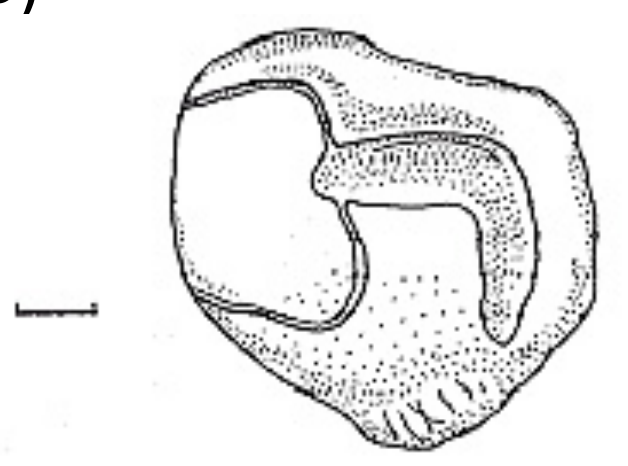

Aplodinotus distortus Nolf, 2003 


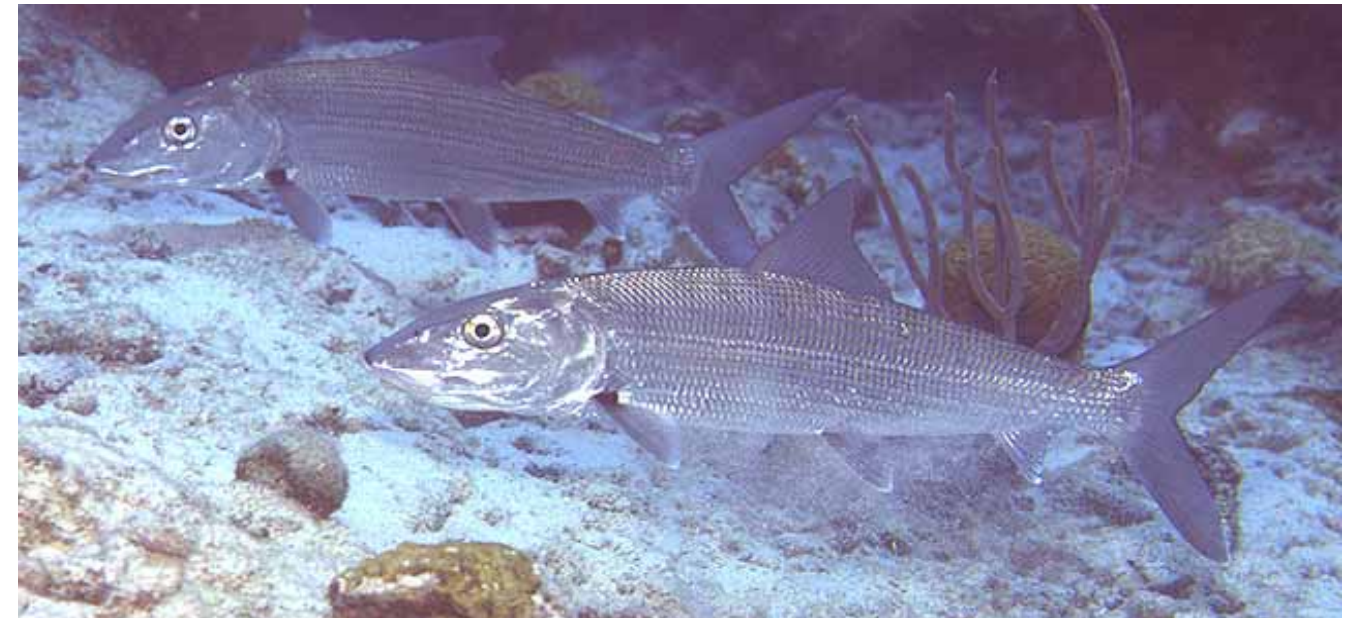

One albulid (bonefishes)

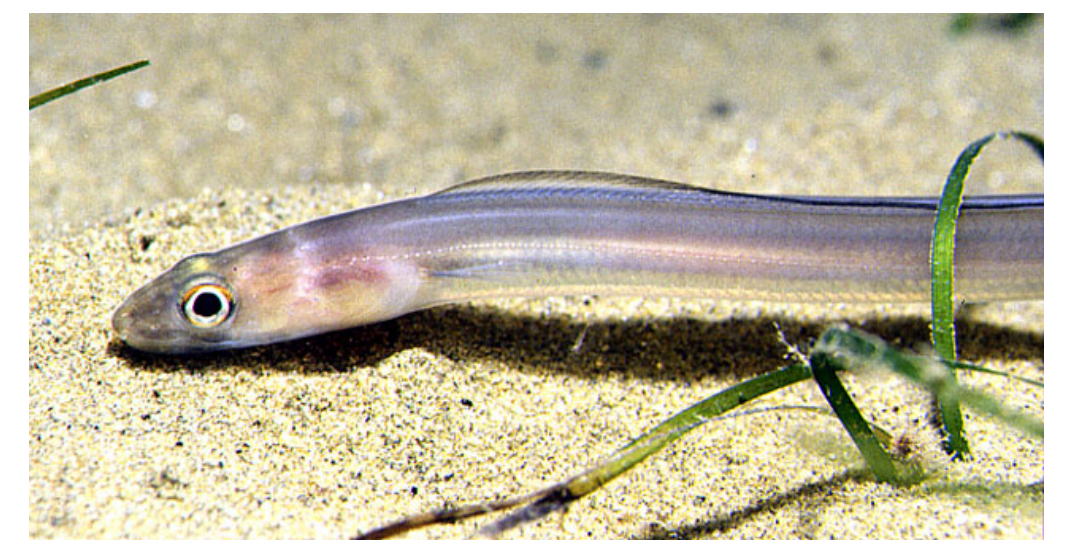

Two taxa of congrids (conger eels)
Closely related Recent fishes represented by otoliths in the Catahoula Formation.

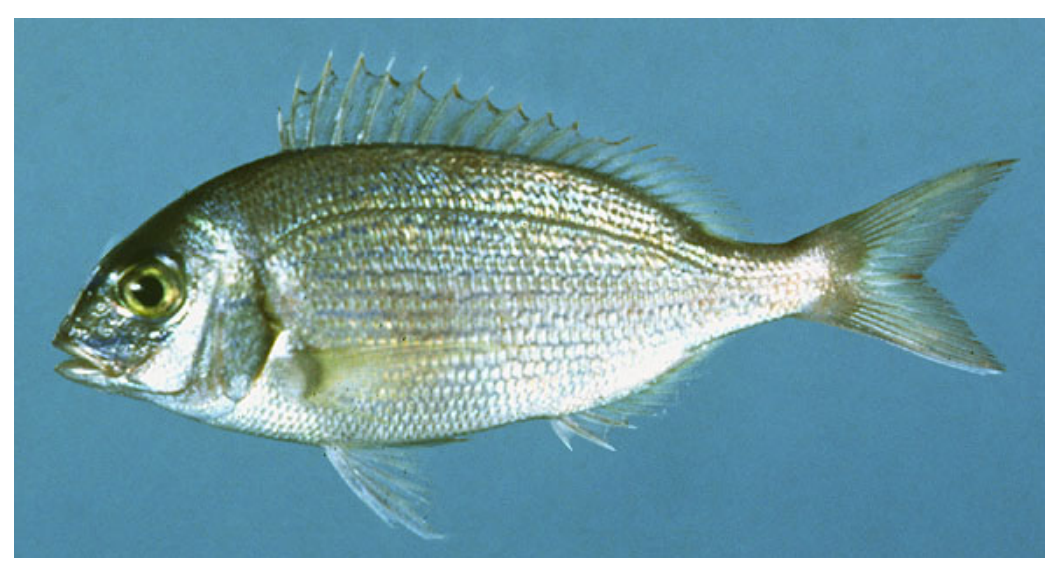

One sparid (porgies)

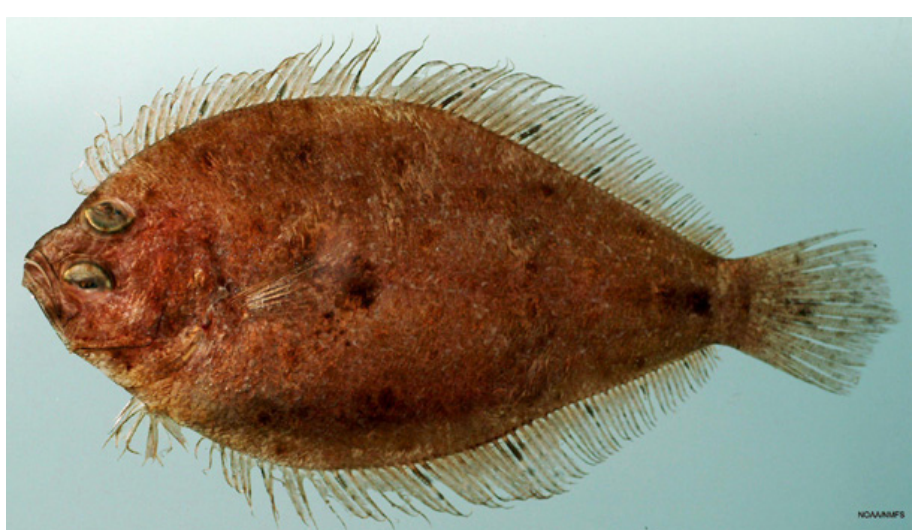

One paralichthyid (large-tooth flounders) 
Closely related Recent fishes represented by otoliths in the Catahoula Formation at the Jones Branch Locality
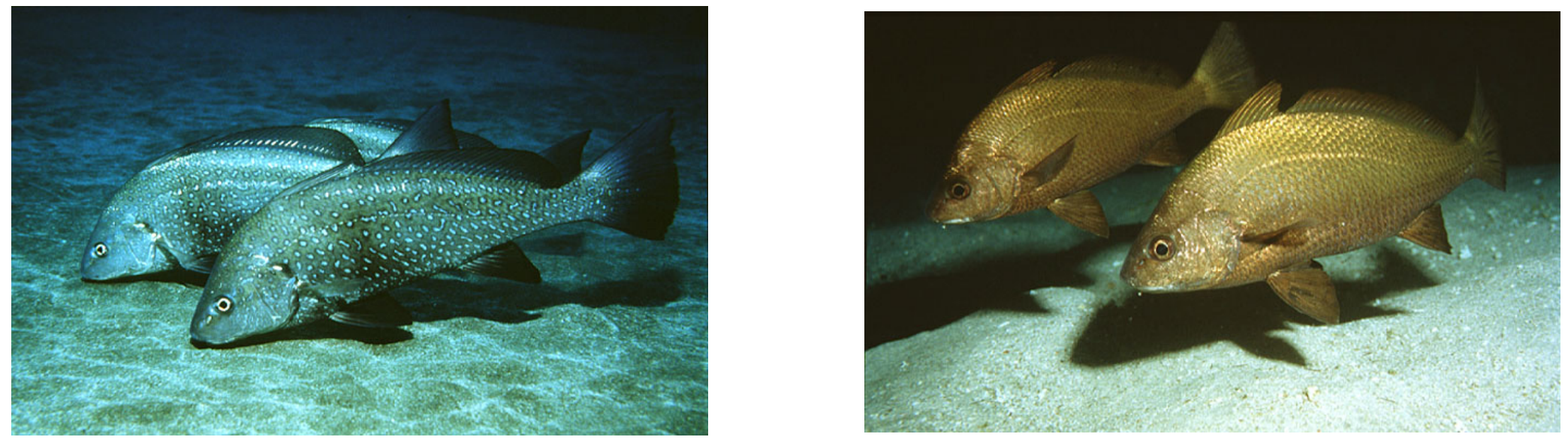

At least four different species of sciaenids or drums
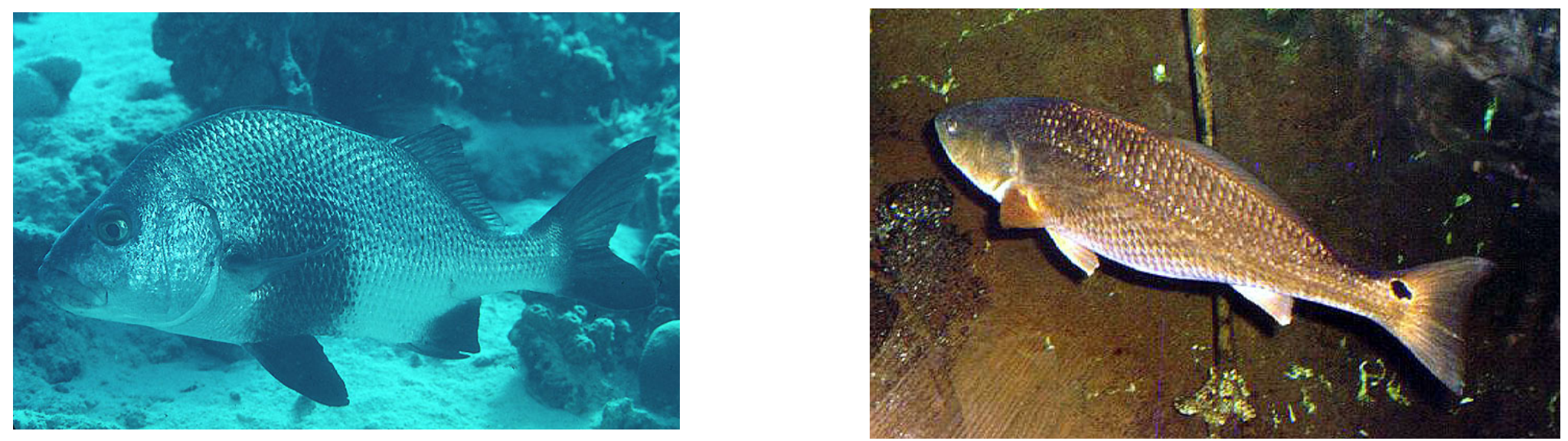


\section{IMPLICATIONS OF SCIAENID OTOLITH SIZE}

Although sciaenids dominated the otolith assemblage numerically and taxonomically, specimens were unusually small.

Complete or nearly complete sciaenids otoliths ranged from approximately $1.65 \mathrm{~mm}$ to $10.27 \mathrm{~mm}$.

However, $98.47 \%$ of the complete sciaenid otoliths identified to species (131 specimens) were $5.99 \mathrm{~mm}$ or less.

Small size is further emphasized in that $91.6 \%$ of the sciaenid otoliths were $3.99 \mathrm{~mm}$ or less.

There is a linear relationship of the size of the otoliths and the age of the fish. 
To understand the significance of the size of Jones Branch sciaenid otoliths, two Recent Gulf of Mexico drums were utilized as analogs. Otoliths were measured for the red drum and black drum from one-year-old to four-years-old.

Size data were also obtained for Aplodinotus grunniens since two of Jones Branch sciaenids were classified in this genus.

Lengths for otoliths of Sciaenops ocellatus (red drum) ranged from 14.65 to $19.24 \mathrm{~mm}$ (one-year-old to four-yearsold), Pogonias cromis (black drum) ranged 10.37 to 16.88 $\mathrm{mm}$ (one-year-old to four), and Aplodinotus grunniens (freshwater drum) ranged from 5.90 to $9.80 \mathrm{~mm}$ (one-yearold to four). 
Applying any of one-year size ranges for the three different species (14.65 mm, $10.37 \mathrm{~mm}$, and $5.90 \mathrm{~mm}$ ), all of the Jones Branch sciaenid otoliths, except for a few specimens, would represent drums that are less than one-year-old (see graph).

Recent ecological data indicate that juvenile black drums prefer shallow, nutrient-rich, turbid waters such as tidal creeks and channels and even freshwater habitats (i.e., reduced salinities).

Other drums, such as the Atlantic croaker, remain in estuaries until they are three-years-old. Many other Gulf of Mexico drums display similar distribution patterns.

Therefore, size (i.e., age of fish) of the Jones Branch sciaenid otoliths appears to indicate an estuarine type environment. 
Size Distribution of Sciaenid Taxa Otoliths

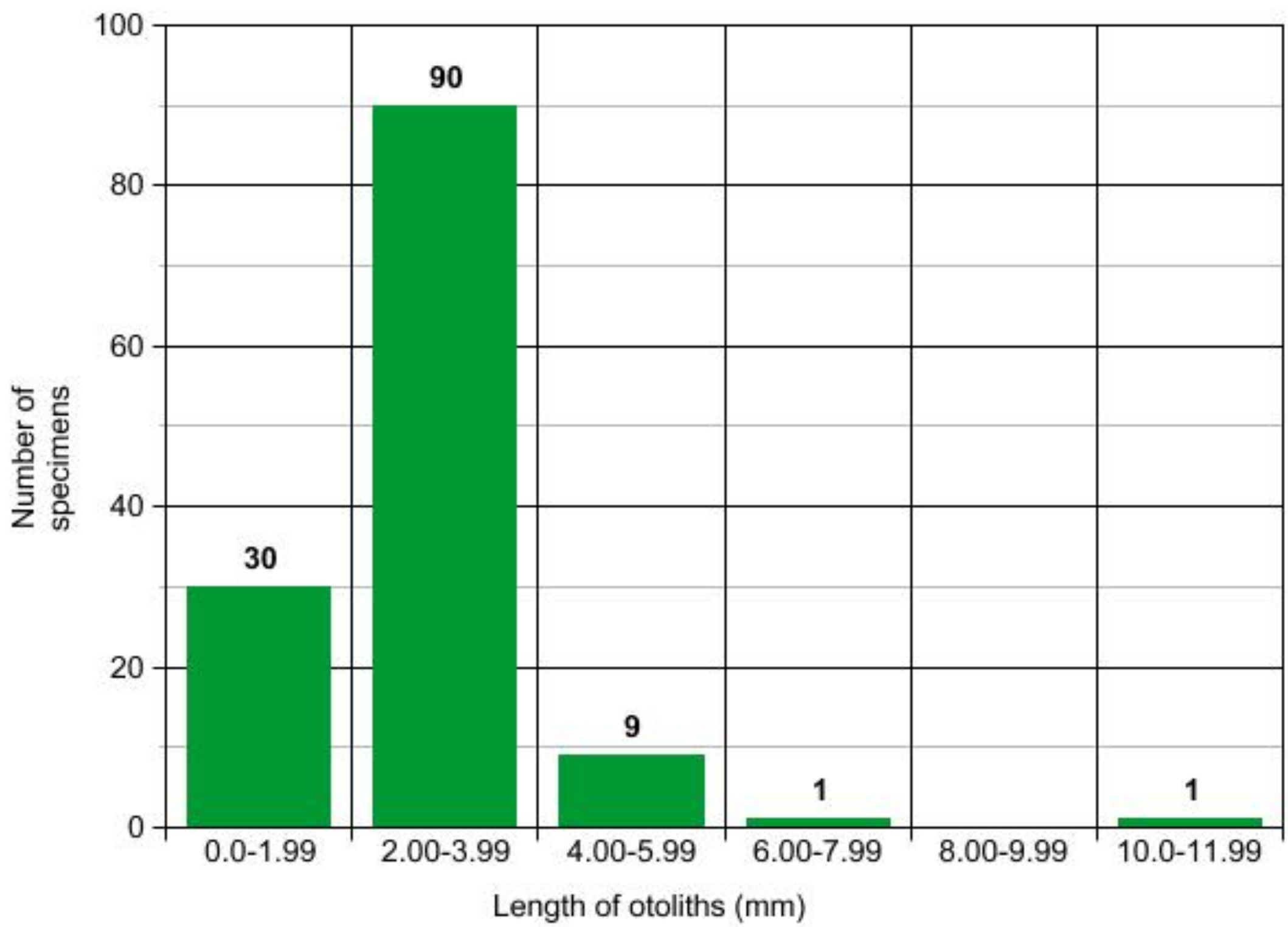




\section{PALEOECOLOGICAL SIGNIFICANCE}

Predominance of the sciaenid otoliths and their size (i.e., age of fish) are strong indicators of estuaries, tidal channels, and passes (reduced salinities). Over $98 \%$ of the sciaenid specimens are smaller than $5.99 \mathrm{~mm}$ and represent fish that are most likely less than one-year-old (larval and juveniles). The highly restricted age composition indicates a specific environment.

Bonefishes (albulids), although very limited, suggest a very shallow marine environment (probably inner shelf or $<20 \mathrm{~m}$ ). Other taxa (conger eels, porgies, and flounders), represented by only five specimens, also indicate extremely shallow, marine waters.

Paleogeography indicated by otoliths appears to confirm several paleogeograpic maps for the area. 


\section{PALEOGEOGRAPHIC IMPLICATIONS}

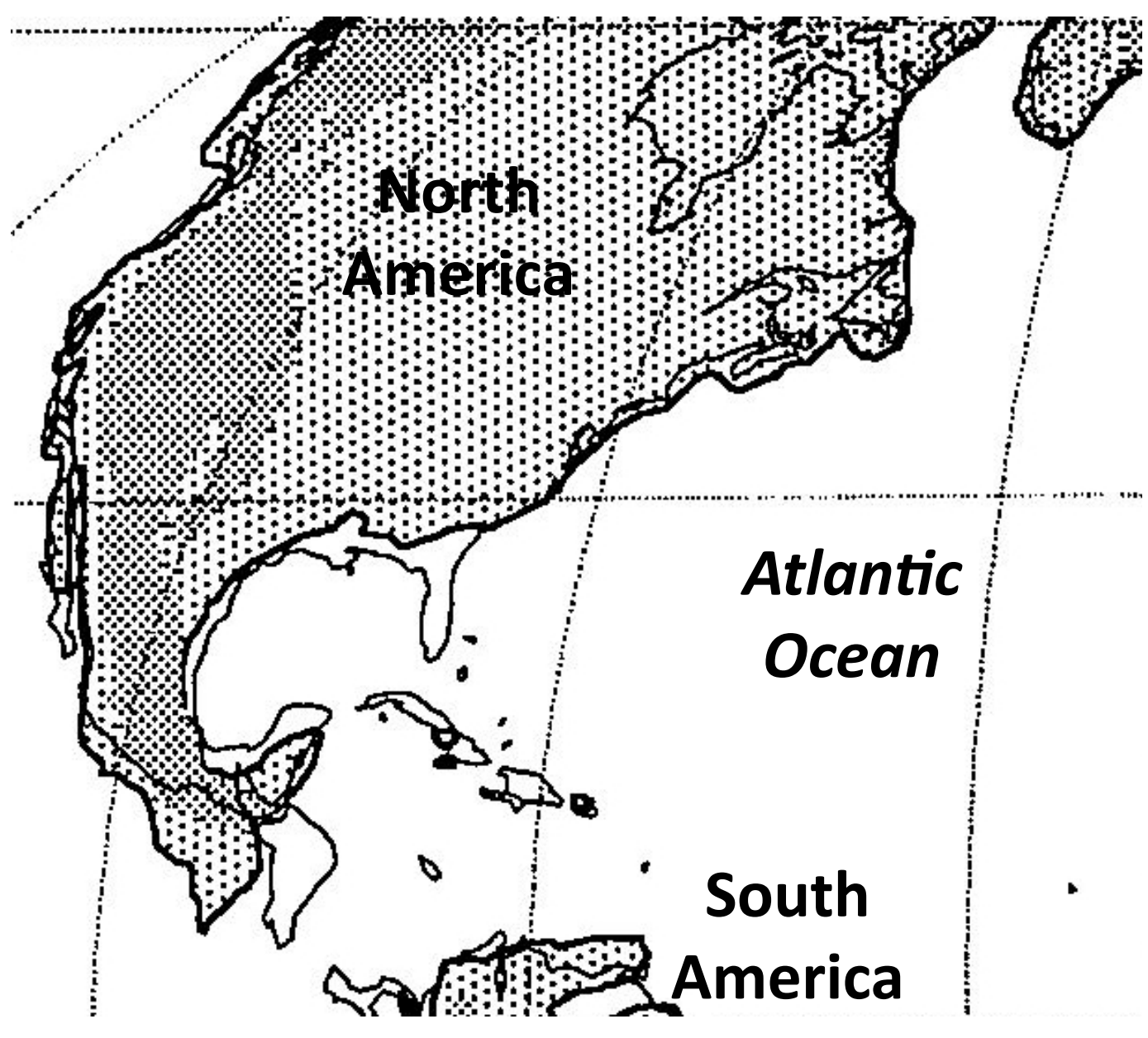

Modified from Atlas of Mesozoic and Cenozoic Coastlines 


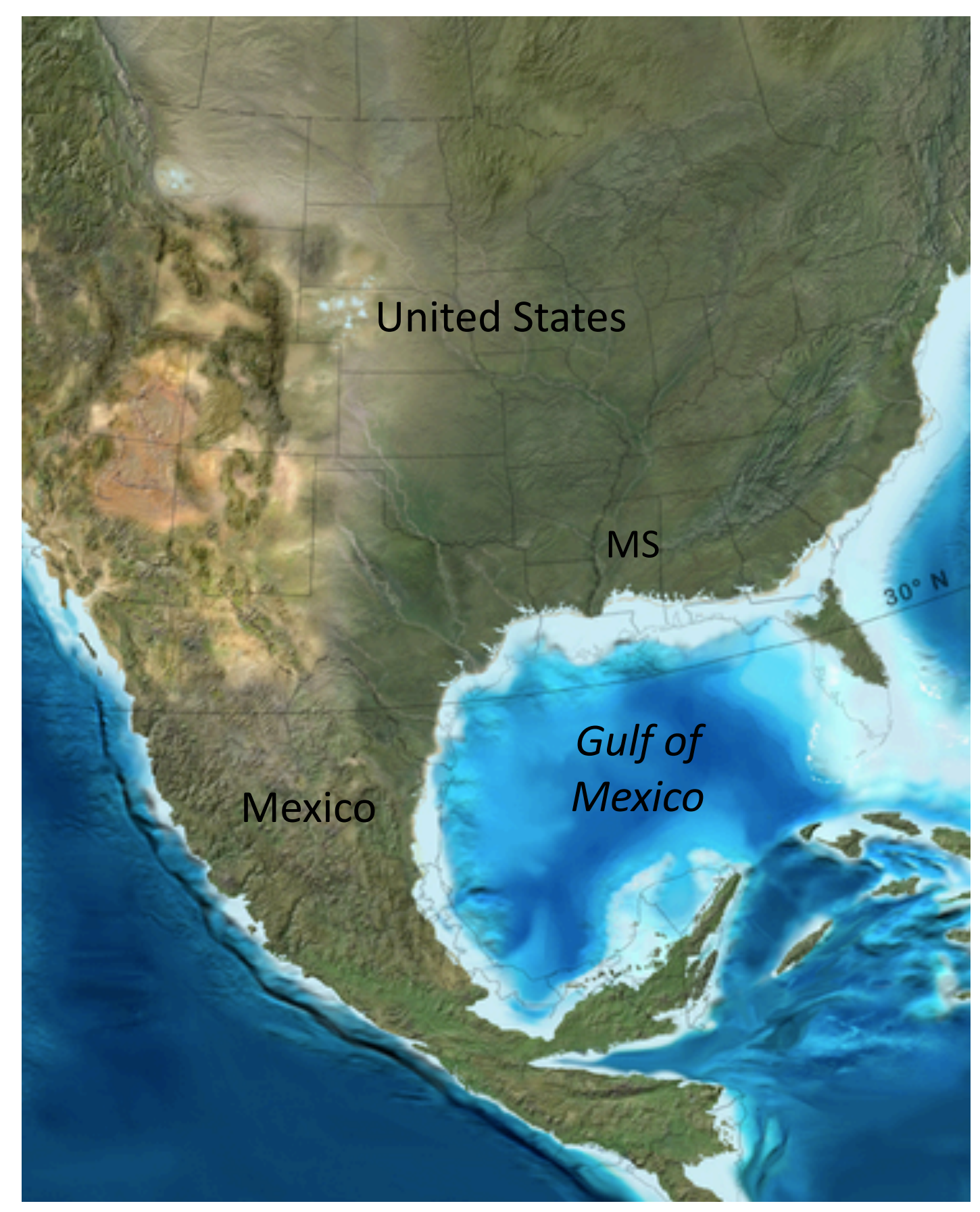

Paleogeography for the Eocene - Oligocene (35 Ma)

Map from "Paleogeographic and Tectonic History of North America - Key Time Slices" (data and map courtesy of Ron Blakey, Colorado Plateau Geosystems, 2013).

Analysis: Map indicates shallow marine conditions and possible estuarine environments for the Jones Branch Locality. This interpretation is also supported by the otolith assemblage. 


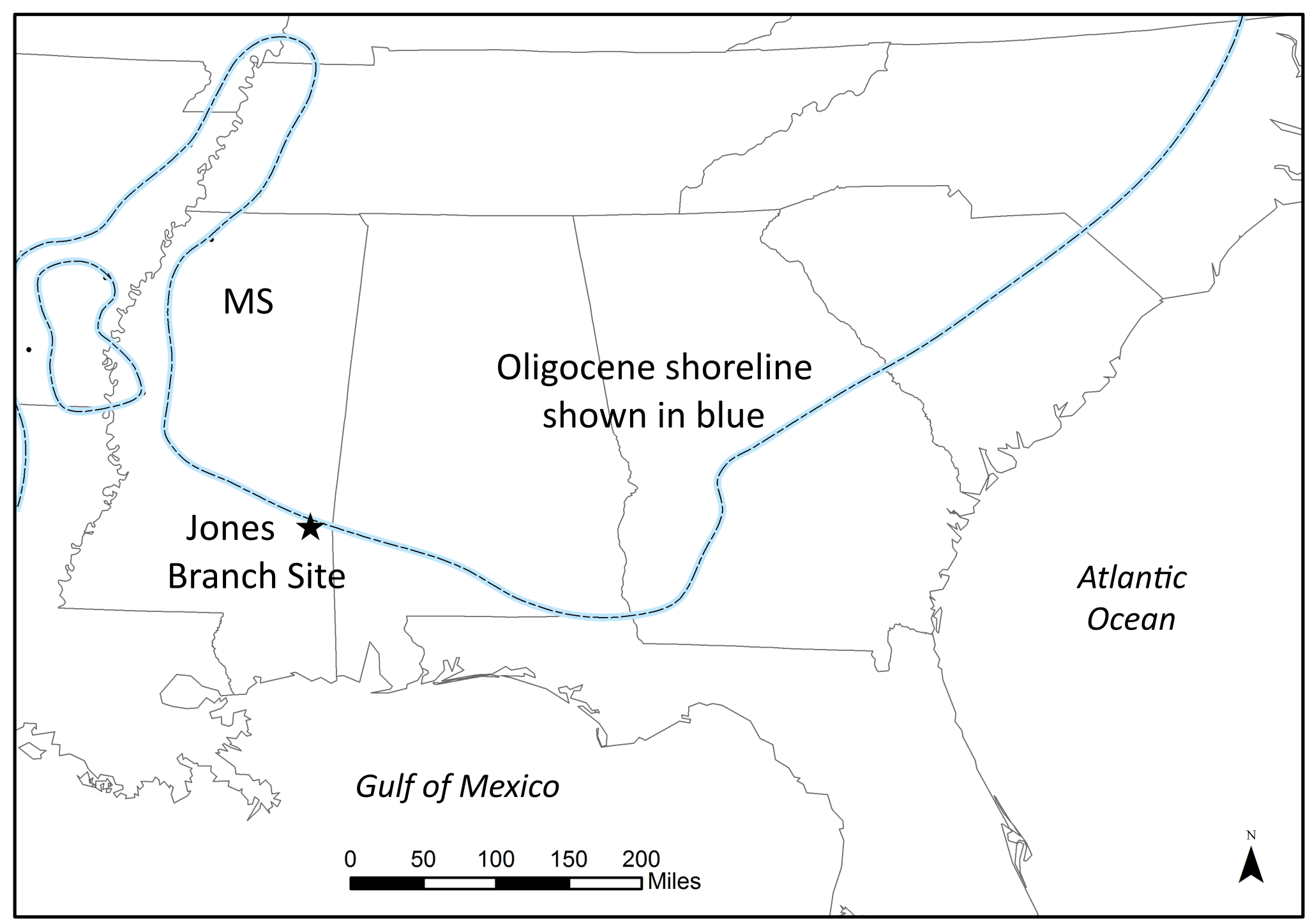

Oligocene paleogeography for southeast U.S. based on mapped Oligocene statescale surface geology (Dr. S. Ebersole , 2016, Geological Survey of Alabama). Otoliths appear to support this scenario and data set extremely well. 


\section{PRELIMINARY CONCLUSIONS}

- Microscopic examination of residue from a shell hash layer in the basal Catahoula Formation (upper Oligocene, Chattian) at the Jones Branch Locality near Waynesboro, Alabama, has produced 295 otoliths that represent at least 5 families and 9 taxa of bony fishes.

- Bony fishes indicated by otoliths were quite restricted in diversity.

- Otolith assemblage was dominated by representatives of the family Sciaenidae, which accounted for $84.75 \%$ of the total otoliths. Three drum taxa, Sciaena pseudoradians, Aplodinotus gemma, and Aplodinotus distortus, were by far the most abundant.

- Several of the sciaenid species (Aplodinotus gemma, Aplodinotus distortus, and "Sciaenida" radians ) are known only from the Gulf Coast Oligocene. 


\section{PRELIMINARY CONCLUSIONS (continued)}

- One of the most unique findings was the size of the sciaenid otoliths, which has a linear relationship to fish age. Over $98 \%$ of the sciaenid otolith specimens were smaller than $5.99 \mathrm{~mm}$.

- Sciaenid otoliths of this size most assuredly represent fish that are less than one-year-old (larval and juveniles). The age composition of the sciaenids is a strong indicator of a specific environment.

- Predominance of the sciaenid otoliths, preferred habitats of sciaenids based on Recent analogs, and size of the drum otoliths (i.e., age of fish) are strong indicators of estuaries, tidal channels, and passes (reduced salinities) in close proximity to shallow marine conditions.

- Whether the otoliths were reworked or syndepositional with the basal Catahoula Formation requires further investigation. 


\section{ACKNOWLEDGEMENTS}

Sincere appreciation is extended to the following:

- George Phillips (Paleontology Curator, Mississippi Museum of Natural Science) and James Starnes (Geologist, Mississippi Office of Geology) who loaned otoliths, accompanied author to site, and assisted in collecting, - Andy Weller from Waynesboro, MS, obtained permission to collect, - Dr. S. Ebersole (Alabama Geological Survey) and Dr. R. Blakey (Colorado Plateau Geosystems) for paleogeographic maps,

- Dr. R. Patzner, Dr. J. E. Randall, Dr. F. Costa, Dr. D. Flescher, Dr. D. Smith (with O. Ozen and E. Irmack), Mr. Barrett Christie, and Ms. Karen Honeycutt graciously allowed the use of pictures of Recent fishes from FishBase,

- Dr. Dirk Nolf, Royal Belgian Institute of Natural Sciences for his support,

- Dr. Melissa Cook, National Marine Fisheries Service, Mississippi Laboratory provided numerous fish for otolith and growth studies.

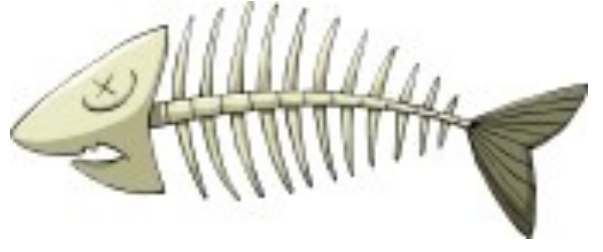




\section{QUESTIONS OR COMMENTS?}

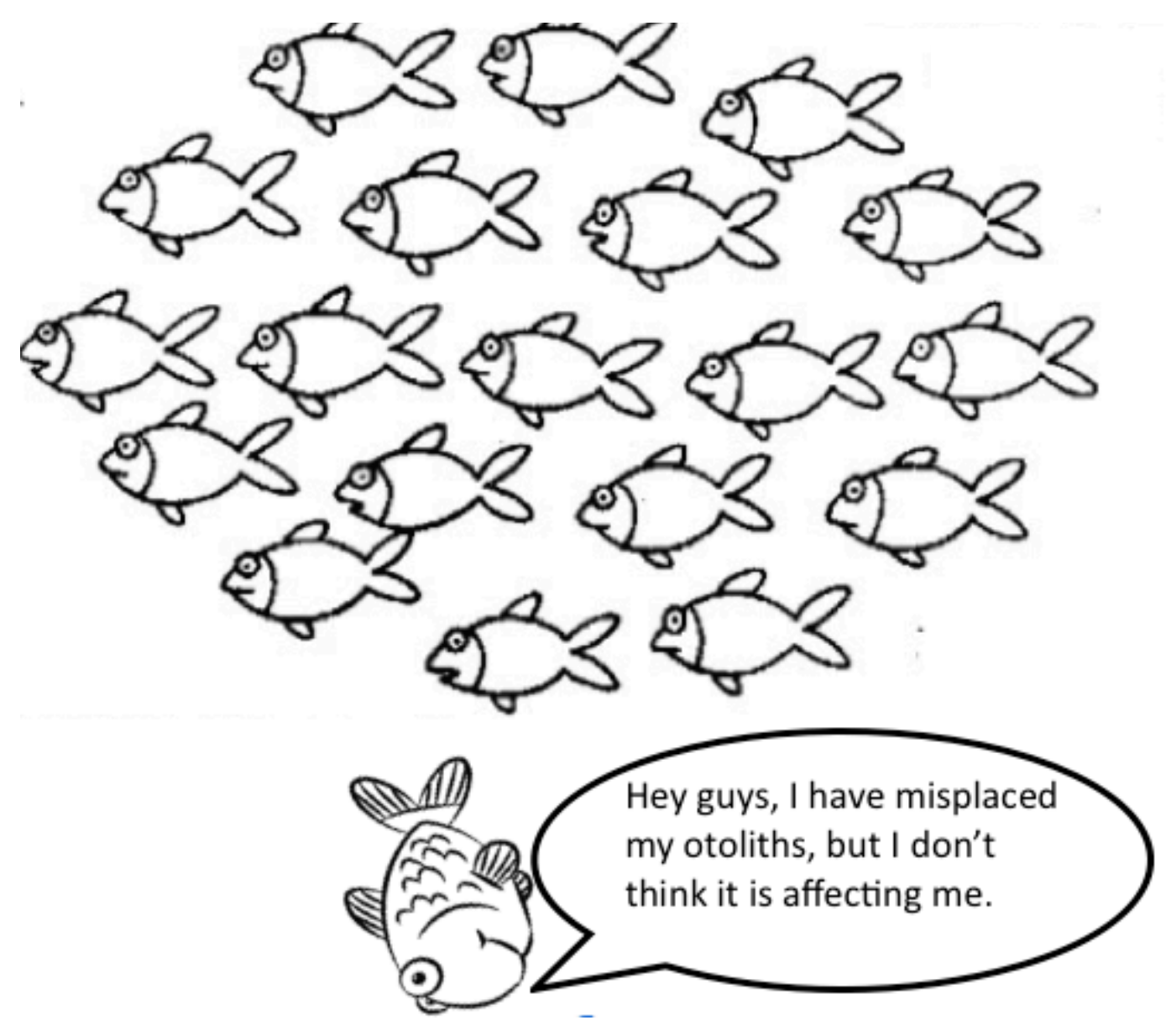

GLS 